\title{
Use of Rice Husk Ash as Cementitious Material in Concrete
}

\author{
Naraindas Bheel \\ Department of Civil Engineering, \\ Mehran University of Engineering and \\ Technology, Jamshoro, Pakistan \\ naraindas04@gmail.com
}

\section{Ali Aizaz Dayo}

Department of Civil Engineering, Mehran University of Engineering and Technology, Jamshoro, Pakistan aliaizaz890@gmail.com

\author{
Abdul Wahab Abro \\ Department of Civil Engineering, \\ Mehran University of Engineering and \\ Technology, Jamshoro, Pakistan \\ ablwab82@gmail.com

\section{Sultan Shaikh} \\ Department of Civil Engineering, \\ Mehran University of Engineering and \\ Technology, Jamshoro, Pakistan \\ sultan11civil@gmail.com
}

\author{
Irfan Ali Shar \\ Department of Civil Engineering, \\ Mehran University of Engineering and \\ Technology, Jamshoro, Pakistan \\ irfanshar2000@gmail.com \\ Zubair Hussain Shaikh \\ Department of Civil Engineering, \\ Mehran University of Engineering and \\ Technology, Jamshoro, Pakistan \\ azubair.shaikh56@gmail.com
}

\begin{abstract}
In this research, rice husk ash (RHA) was used as a partial substitute for cement in concrete to reduce its cost, and alternative processing methods using agricultural/industrial waste were found. The main objective of this study was to determine the fresh (flowability) and hardened (splitting tensile strength and compressive strength) concrete properties using RHA at $0 \%, 5 \%, 10 \%, 15 \%$ and $20 \%$ by weight. A total of 90 concrete samples (45 cubes and 45 cylinders) were prepared and cured on 7, 14, and 28 days to the design of target strength $28 \mathrm{~N} / \mathrm{mm}^{2}$, and ultimately, these concrete specimens were tested on UTM. Three concrete specimens were cast for each proportion and ultimately the average of the three concrete samples was taken as the final result. The flowability of fresh concrete decreases with increasing content of RHA in concrete. The results showed that the compressive and tensile strength of the concrete specimens increased by $11.8 \%$ and $7.31 \%$, respectively by using $10 \%$ RHA at 28 days curing.
\end{abstract}

Keywords-rice husk ash; cement replacement material; improved strength; reduced construction cost; utilizing disposal waste

\section{INTRODUCTION}

Concrete is widely and globally used throughout the history of humankind [1]. Concrete is a mixture of sand and crushed rock combined together by a hardened paste of hydraulic cement and water [2]. The increased use of concrete is going to grow the demand for its ingredients' resources (cement, sand, and gravel). The high rate of concrete constituents is increasing rapidly and hence there is a requirement for an unconventional material that is low-cost and readily presented that will also give a similar or greater strength when used for concrete [3]. Cement is one of the constituents of concrete which is costly and its production releases large amounts of $\mathrm{CO}_{2}$ during its manufacturing [4-8]. Manufacturing one tonne of cement releases about one tonne of $\mathrm{CO}_{2}$ in the atmosphere while 1.6 tonnes of natural resources are required to produce about one tonne of cement [9-11]. In many studies the cement is partially replaced by agricultural/industrial waste such as glass powder, sugar cane bagasse ash, rice husk ash (RHA), blast furnace slag, maize cob ash, millet husk ash, fly ash etc. in order to reduce cost, waste and $\mathrm{CO}_{2}$ emissions while these resources are easily available $[9,12]$. RHA is the by-product of agricultural waste [13-15], it is considered unwanted and is mostly air burned $[16,17]$. Currently disposing of agro/industrial waste is a serious problem. One of these agro wastes is rice husk. Rice husk annual produced quantity is about 120 million tonnes per year in the paddy field [17-19]. The husk manufactured from rice processing is either burnt or dumped. Rice husk is burnt at a certain temperature under atmosphere. RHA possess $85 \%$ of silica content that is known as non-crystalline silica and it could be utilized as partial cement replacement material [2024]. RHA is measured as a highly pozzolanic material [25-29] and it can be used as an additional material in concrete decreasing the environmental problem.

A research study of the hardening properties of concrete was carried out in [30] using 10\% RHA. In this study, concrete samples were cured and tested after 7, 14, 28, and 56 days, using a mixing ratio of 1:2:4 with water-cement ratio 0.45 , 0.50 , and 0.60 . The results showed that the compressive and tensile strengths increased by $14.51 \%$ and $10.71 \%$, respectively, at 0.45 water-cement ratio when $10 \%$ RHA was used in concrete with a curing time of 56 days. Authors in [31] reported that RHA is beneficial to reduce the temperature of concrete as compared to plain cement concrete. Authors in [32] carried out researched on the hardened properties of concrete blended with cement by $5 \%, 10 \%, 15 \%$ and $20 \%$ weight. The concrete samples were designed for target strength of $25 \mathrm{~N} / \mathrm{mm}^{2}$ and were cured for 7 and 28 days. The result was that the crushing strength improved by $15.74 \%$ when using $10 \%$ of RHA in concrete at 28 days [32]. RHA plays an essential role in the characteristics of cementitious materials [33]. The size of 
the RHA particles is finer than OPC, which augments concrete properties [34]. The size of RHA particles is around 25 microns which makes RHA capable of playing a vital role as filler in cement [35]. In this experimental study, RHA was blended in concrete by weight in proportions up to $20 \%$.

\section{RESEARCH METHODOLOGY}

Research was conducted on the fresh and hardened properties of concrete by using $0 \%, 5 \%, 10 \%, 15 \%$ and $20 \%$ of RHA as cement substituent material in concrete. A total of 90 concrete samples ( 45 cubes and 45 cylinders) were prepared and cured at 7,14 , and 28 days to the design of target strength of $28 \mathrm{~N} / \mathrm{mm}^{2}$. To get an optimum mix, a number of trail mixes are completed using variable cement (binder), coarse aggregates, fine aggregates, and water. While getting the desirable mix, RHA was used as cement substituent material to determine the characteristics strength of concrete specimens and ultimately, these concrete specimens were tested on UTM while obeying the British Standard (BS) code. In this study, the concrete cubes were cast for compressive strength and cylinders were cast for splitting tensile strength. Three concrete specimens were cast for each proportion and finally, an average value of the three specimens was taken as the final result. This research work was completed in the concrete laboratory of the Department of Civil Engineering, College of Science and Technology, Hyderabad, Sindh, Pakistan.

\section{MATERIALS USED}

\section{A. Cement}

The cement that was used is available locally in the market under the brand name Pak land.

\section{B. Fine Aggregates}

Hilly sand was used as fine aggregates of Zone-II which passed through Sieve No. $4(4.75 \mathrm{~mm})$. The fineness modulus, water absorption and specific gravity of fine aggregates are $2.61,1.8 \%$ and 2.60 respectively.

\section{Coarse Aggregates}

The coarse aggregates used were $20 \mathrm{~mm}$ in size and were available in the local market. The water absorption and the specific gravity of coarse aggregates were $1.4 \%$ and 2.73 respectively.

\section{Rice Husk Ash}

Rice husk was collected from the region of Sakrand and it was air-dried. RHA was acquired by using uncontrolled temperature burning method. The desired ash was sieved through \#30 sieves.

\section{E. Water}

Drinking water, available in the lab, was used.

\section{RESULTS AND DISCUSSION}

\section{A. Fresh Concrete Workability}

The flow of fresh concrete was conducted by slump cone having the dimensions of $10 \mathrm{~cm}$ top diameter, $20 \mathrm{~cm}$ bottom diameter and $30 \mathrm{~cm}$ height. The maximum flow of fresh concrete was $65 \mathrm{~mm}$ while using $0 \%$ RHA as cement substituent material in concrete and the minimum value of workability was $25 \mathrm{~mm}$ at $20 \%$ RHA by weight. It was concluded that the flow of fresh concrete decreases with an increase in the amount of RHA in concrete. The experimental results are shown in Figure1.

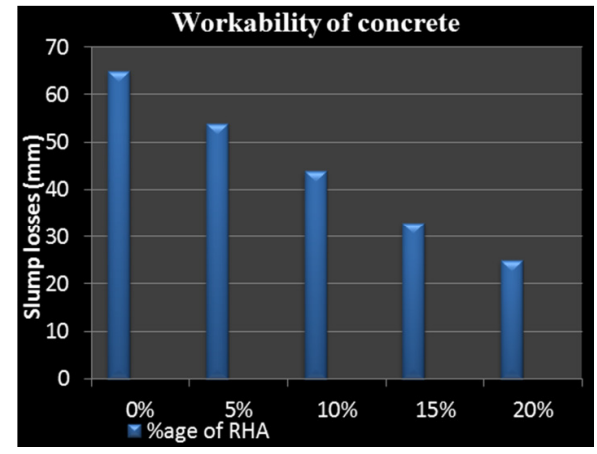

Fig. 1. Workability of fresh concrete

\section{B. Compressive Strength}

Compressive strength test were conducted on cubes $(100 \mathrm{~mm} \times 100 \mathrm{~mm} \times 100 \mathrm{~mm})$ by using different RHA percentages. Three specimens were cast for each proportion and ultimately, an average value of these three concrete specimens was taken as the final result. The compressive strength was maximum at $10 \%$ of RHA used as cement substituent material in concrete and minimum at $20 \%$ of RHA, at 7,14 , and 28 days. The results are shown in Figure 2.

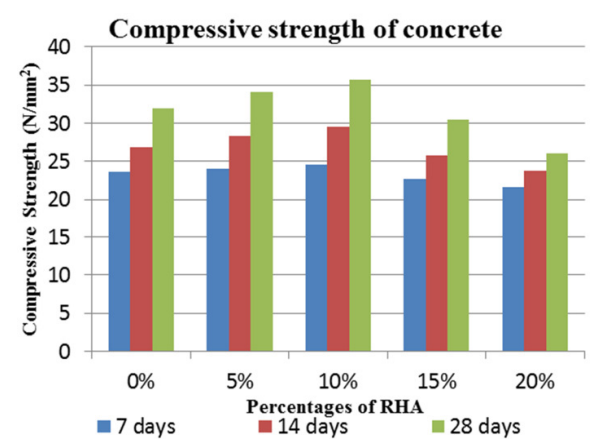

Fig. 2. Compressive strength of concrete at 7, 14, and 28 days

\section{Splitting Tensile Strength}

Splitting tensile strength tests were conducted on cylinders $(200 \mathrm{~mm} \times 100 \mathrm{~mm})$ of various RHA percentages which were cured at 7,14, and 28 days. Three concrete samples were cast for each proportion and an average was taken as the final result. The maximum splitting tensile strength of concrete was noted at $10 \%$ RHA specimens and the minimum splitting strength of concrete was recorded at $20 \%$. The cylinders were tested on UTM. The experimental work results are shown in Figure 3.

\section{CONCLUSIONS}

- The flow of fresh concrete was noted maximum while using $0 \%$ RHA as cement substituent material in concrete. The minimum value of workability was recorded at $20 \%$ RHA. 
- It was concluded that the flow of fresh concrete decreases with an increase in the amount of RHA in concrete.

- The compressive strength was maximum at $10 \%$ RHA concrete and minimum at $20 \%$ RHA concrete at 7,14 , and 28 days.

- The maximum splitting tensile strength of concrete was noted at $10 \%$ RHA concrete and the minimum splitting strength was recorded at $20 \%$ RHA concrete at 7,14 , and 28 days.

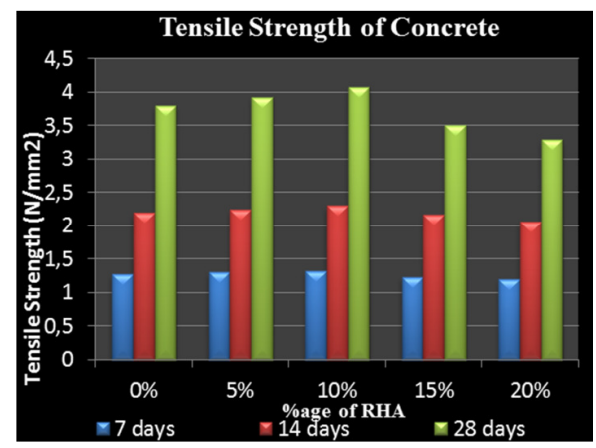

Fig. 3. Split tensile strength at 7,14 , and 28 days

\section{REFERENCES}

[1] A. Manimaran, M. Somasundaram, P. T. Ravichandran, "Experimental study on partial replacement of coarse aggregate by bamboo and fine aggregate by quarry dust in concrete", International Journal of Civil Engineering and Technology, Vol. 8, No. 8, pp. 1019-1027, 2017

[2] M. K. Nemati, "Chapter 5: Aggregates for Concrete", in: Concrete Technology-Fiber Reinforced Concrete Final Report, University of Washington, 2013

[3] P. A. Shirule, A. Rahman, R. D. Gupta, "Partial Replacement of Cement With Marble Dust Powder", International Journal of Advanced Engineering and Studies, Vol. 1, No. 3, pp. 175-177, 2012

[4] J. Alex, J. Dhanalakshmi, B. Ambedkar, "Experimental investigation on rice husk ash as cement replacement on concrete production", Construction and Build Materials, Vol. 127, pp. 353-362, 2016

[5] E. Aprianti, P. Shafgh, S. Bahri, J. Nodeh, "Supplementary cementitious materials origin from agricultural wastes-a review", Construction and Building Materials, Vol. 74, pp. 176-187, 2015

[6] R. Khan, A. Jabbar, I. Ahmad, W. Khan, A. N. Khan, J. Mirza, "Reduction in environmental problems using rice-husk ash in concrete", Construction and Building Materials, Vol. 30, pp. 360-365, 2012

[7] O. A. U. Uche, M. Adamu, M. A. Bahuddeen, "Influence of Millet Husk Ash on The Properties of Plain Concrete", Epistemics in Science, Engineering and Technology, Vol. 2, No. 2, pp. 68-73, 2012

[8] N. Bheel, S. L. Meghwar, S. Sohu, A. R. Khoso, A. Kumar, Z. H. Shaikh, "Experimental Study on Recycled Concrete Aggregates with Rice Husk Ash as Partial Cement Replacement", Civil Engineering Journal, Vol. 4, No. 10, pp. 2476-3055, 2018

[9] J. P. Broomfield, Corrosion of Steel in Concrete, Understanding, Investigation, and Repair, E \& FN SPON, 2006

[10] P. Schiessl, Corrosion of Steel in Concrete, Report of the Technical Committee, 60-CSC Rilem, Chapman and Hall, 1998

[11] H. Muga, K. Betz, J. Walker, C. Pranger, A. Vidor, Development of Appropriate and Sustainable Construction Materials, Sustainable Futures Institute, Michigan Technological University, 2005

[12] R. R. Hussain, T. Ishida, "Critical Carbonation Depth for Initiation of Steel Corrosion in Fully Carbonated Concrete and Development of Electrochemical Carbonation Induced Corrosion Model", International Journal of Electrochemical Science, Vol. 4, pp. 1178-1195, 2009
[13] N. Kad, M. Vinod, "Review research paper on influence of rice husk ash on the properties of concrete", International Journal of Research, Vol. 2, No. 5, pp. 873-877, 2015

[14] M. Anwar, T. Miyagawa, M. Gaweesh, "Using rice husk ash as a cement replacement material in concrete", International Conference on the Science and Engineering of Recycling for Environmental Protection, Harrogate, UK, May 31-June 2, 2000

[15] S. D. Nagrale, H. Hemant, R. M. Pankaj, "Utilization of rice husk ash", International Journal of Engineering Research and Applications, Vol. 2, No. 4, pp. 1-5, 2012

[16] I. B. Ologunagba, A. S. Daramola, A. O. Aliu, "Feasibility of using Rice Husk Ash as Partial Replacement for Concrete", International Journal of Engineering Trends and Technology, Vol. 30, No. 5, pp. 267-269, 2015

[17] A. N. Givi, S. A. Rashid,F. N. A. Aziz, M. A. M. Salleh, "Contribution of Rice Husk Ash to the Properties of Mortar and Concrete: A Review", Journal of American Science, Vol. 6, No. 3, pp: 157-165, 2010

[18] H. B. Mahmud, N. Anjang, A. Hamid, K. Y. Chin, "Production of high strength concrete incorporating an agricultural waste-rice husk ash", 2nd International Conference on Chemical, Biological and Environmental Engineering, Cairo, Egypt, November 2-4, 2010

[19] H. Thanh, K. Siewert, H. M. Ludwig, "Alkali-silica reaction in mortar formulated from self-compacting high-performance concrete containing rice husk ash", Construction and Building Materials, Vol. 88, pp. 10-19, 2015

[20] R. G. Smith, G. A. Kamwanja, "The use of rice husk for making a cementitious material", Joint Symposium on the Use of Vegetable Plants and their Fibers as Building Material, Baghdad, Iraq,1986

[21] M. H. Zhang, R. Lastra, V. M. Malhotra, "Rice husk ash paste and concrete: some aspects of hydration and the microstructure of the interfacial zone between the aggregate and paste", Cement and Concrete Research, Vol. 6, No. 26, pp. 963-977, 1996

[22] N. P. Hasparyk, P. J. M. Monteiro, H. Carasek, "Effect of silica fume and rice husk ash on alkali-silica reaction", Aci Structural Journal, Vol. 4, No. 97, pp. 486-492, 2000

[23] K. Sakr, "Effects of silica fume and rice husk ash on the properties of heavy weight concrete", Journal of Materials in Civil Engineering, Vol. 18, No. 3, pp. 367-376, 2006

[24] V. Sata, C. Jaturapitakkul, K. Kiattikomol, "Influence of pozzolan from various by-product materials on mechanical properties of high-strength concrete", Construction and Building Materials, Vol. 21, No. 7, pp. $1589-1598,2007$

[25] M. M. Tashima, C. A. R. Da Silva, J. L. Akasaki, M. B. Barbosa, "The possibility of adding the rice husk ash (RHA) to the concrete", in: Proceedings of the IRILEM Conference on the Use of Recycled Materials in Building and Structures, pp. 778-786, RILEM, 2004

[26] S. K. Antiohos, J. G. Tapali, M. Zervaki, J. Sousa-Coutinho, S. Tsimas, V. G. Papadakis, "Low embodied energy cement containing untreated Rha: a strength development and durability study", Construction and Building Materials, Vol. 49, pp. 455-463, 2013

[27] L. Prasittisopin, D. Trejo, "Hydration and phase formation of blended cementitious systems incorporating chemically transformed rice husk ash", Cement and Concrete Composites, Vol. 59, pp. 100-106, 2015

[28] M. F. M. Zain, M. N. Islam, F. Mahmud, M. A. Jamil, "Production of rice husk ash for use in concrete as a supplementary cementitious material", Construction and Building Materials, Vol. 25, No. 2, pp. 798805,2011

[29] R. Bie, X. Song, Q. Liu, X. Ji, P. Chen, "Studies on effects of burning conditions and rice husk ash (RHA) blending amount on the mechanical behavior of cement", Cement and Concrete Composites, Vol. 55, pp. $162-168,2015$

[30] N. D. Bheel, S. L. Meghwar, S. A. Abbasi, L. C. Marwari, J. A. Mugeri, R. A. Abbasi, "Effect of rice husk ash and water-cement ratio on strength of concrete", International Civil Engineering Journal, Vol. 4, No. 10, pp. 2373-2382, 2018

[31] P. K. Mehta, D. Pirtz, "Use of rice husk ash to reduce the temperature in high strength mass concrete", International Concrete Abstracts Portal, Vol. 75, No. 2, pp. 60-63, 1978 
[32] M. Akhter, "Experimental Study on Effect of Wood Ash on Strength of Concrete", International Research Journal of Engineering and Technology, Vol. 4, No. 7, pp. 1252-1254, 2017

[33] V. M. Malhotra, P. K. Mehta, Pozzolanic and Cementitious Materials, Taylor \& Francis, 2004

[34] A. M. Nevile, J. J. Brooks, Concrete Technology, Longman Scientific and Technical, 1990

[35] S. Rukzon, P. Chindaprasirt, R. Mahachai, "Effect of grinding on chemical and physical properties of rice husk ash", International Journal of Minerals, Metallurgy and Materials, Vol. 16, No. 2, pp. 242-247, 2009 